\title{
COMPUTER MEANS TO FORM PROFESSIONAL COMPETENCE OF FUTURE ECOLOGISTS AND BIOLOGISTS IN UKRAINE
}

\author{
Mykhailo Sherman ${ }^{1}$ \\ Yaroslava Samchynska ${ }^{2}$
}

DOI: https://doi.org/10.30525/978-9934-588-38-9-22

Abstract. The purpose of the paper is creation and use of the informational system of educational appointment on rare species of animals as a computer tool for the formation of professional competence of future ecologists and biologists in modern higher education in Ukraine. Methodology. On the basis of the analysis of similar web resources, the main and additional requirements for the information resource of animals, which take into account the shortcomings of existing information resources, are formulated. The project was implemented using the Python programming language, the Django framework, the Adobe Photoshop graphics editor. Results of the survey. The main stages of the «Little Zoo» information and reference system development process are considered. Thanks to the resource users will be able to search for a rare species of animal according to one or more characteristics. The system also provides for the possibility of students learning materials by sorting articles about animals in the right order. The description of the functional of the information-reference system is presented. The developed system will allow users (the future ecologists) to save time compared to the usual search, which is presented in most of the existing web resources of environmental focus. Practical implications. Information system is successfully used at the Kherson State University in studying the discipline «Informatics and Systemology» by students of specialties 101 «Ecology» and 014 «Secondary education (Biology)», as well

\footnotetext{
${ }^{1}$ Doctor of Pedagogical Sciences, Professor of the Chair of Informatics, Software Engineering and Economic Cybernetics, Kherson State University, Ukraine

${ }^{2} \mathrm{PhD}$ in Economic Science, Associate Professor of the Chair of Informatics, Software Engineering and Economic Cybernetics, Kherson State University, Ukraine
} 
as in studying the discipline «Information technologies and technical means of correctional training» by students of specialty 016 «Special Education». The acquaintance and work of the students with the learning resource is carried out within the framework of such classroom topics as «Information Systems and Technologies», «Possibilities of Using Information Technologies in Future Professional Activities». The interest of students in this reference system is due to the fact that registered users can add their own articles about rare animals, thereby expanding and updating the database of the resource. Such an active creative task contributes to the development of cognitive and intellectual activity, students' information competence, and also adapts to the real conditions of future professional activity in the field of ecology, biology and special education.

\section{Introduction}

Information and communication technologies are the most effective means of working out large volumes of various types of information both for educational and professional purposes. The discipline «Informatics and Systemology», as well as related items, is an integral part of the information competence of students of environmental specialties in higher education institutions, which in turn significantly affects the level of their professional training.

Information technologies have become essential components of the development of a modern educational environment at all its levels - from student to management of educational institution and educational system. This is due to the fact that the priority task of education in the training of ecologists who are competitive in the society is the ability to operate with such technologies and knowledge that can meet the needs of the modern labor market and are able to prepare for the implementation of complex tasks in the future. It is not just about the ability to apply the acquired knowledge, but also to be prepared to change and adapt to the new needs of the labor market, to manage information in the educational and scientific spheres, to actively act, to study throughout life. In the context of reforming education, the model of higher education changes, as well as the role of the teacher as a participant in the educational process [1, p. 22]. The process of studying in higher education institutions is transformed from the system of knowledge transfer to the system of their independent acquisition by students, the search for solutions to problems through research activi- 
ties, inherent models of studying the level of higher education «bachelor». A student in the process of learning is gradually becoming the manager of his future. But the development process of such a person requires constant updating of knowledge and self-improvement of the teacher himself $[25$, p. 28]. That is why the electronic educational resources, which are an integral part of the educational process, are actively used in the training of students of the «bachelor» higher education level.

However, the development of professional competence of future ecologists in the conditions of a modern university is characterized by contradictions, the main of which in the context of our consideration are the following:

- insufficient account in the content of the disciplines «Informatics and Systemology», «Information Technologies» needs of the way by which the training of future environmentalists is carried out;

- actual realization in the process of teaching these disciplines is only a general development function, while improving the quality of professional computer-information training of future environmentalists remains a secondary task;

- insufficiently clearly identified and outlined interdisciplinary connections between professionally oriented environmental disciplines and computer science with related disciplines [1, p. 22].

The solution of the above contradictions, according to scientists M.I. Sherman, N.V. Stepanenko [2, p. 38; 3, p. 8], G.A. Biletskaya [4, p. 22], I.P. Kovalchuk [5, p. 180] is possible subject to the systematic implementation of the principles of professional orientation, professional compliance, integrity, continuity, consistency, logical inconsistency in the teaching of computer and information disciplines, both in the study of theoretical material, and in the implementation of practical tasks and independent work of students in non-auditing time.

In our opinion, it is the modern information and communication technologies capable to provide comprehensive system of training for environmental students, the basis of which is the application of acquired theoretical knowledge, skills and abilities in practice. In this context, the development of a professionally oriented informative and reference system of educational purposes, aimed at solving the tasks of computer-information training of future environmentalists, is sufficiently timely, expedient and relevant task. 


\section{Analysis of recent research and publications}

Scientists I.P. Kovalchuk (2002), A.A. Gorelov (1998) considered the formation and development of environmental education for a long time. The result of the research of leading environmental specialists was approved by the Board of the Ministry of Education and Science «Concept of Ukrainian ecological education» [7, p. 20-29]. Considerable attention in this document is paid to the professional training of specialists who must have basic environmental education at the level of the existing world requirements.

Considering the structure of modern ecology as a direction from the point of view of professional training of environmentalists, scientists N.V. Stepanenko, M.I. Sherman [1, p. 24-28; 3, p. 8; 9, p. 204], I.P. Kovalchuk [8, p. 155-156], G.A. Biletska [4, p. 18; 17], M. Simonovska [10, p. 79] distinguish the following basic disciplines: ecology, mathematics, computer science, statistics, cartography. Providing high-quality educational and controlling interdisciplinary connections between them is an important pedagogical task in the training of future ecologists, whose solution in the context of teaching the disciplines «Informatics and Systemology», «Information Technologies» is aimed at this study.

In order to ensure the quality of education for obtaining an educational degree, the bachelor's degree in Ecology must take into account the peculiarities of vocational training and the selection of innovative technologies for conducting studies on the basis of personality-activity, competence and system-based approach. As O. Spivakovsky points out, today in most higher education institutions traditional approaches to the organization of vocational education are used, in which the student feels as the object of pedagogical influences that does not require his initiative, creativity, activation of reflection, does not contribute to solve these problems and does not provide proper level of education, scientific and professionalism [13, p. 176]. Creation of pedagogical conditions, namely, the partnership activities of the teacher and the student, introduction of web technologies, interactive forms and methods of work, optimization of the educational process for the formation of professionally important qualities, provision of motivation to the students for research and creative activity in the final result lead to the achievement of the goal - the development of professional competence of ecologists with the level of higher education «Bachelor» [25, p. 29]. 
In this regard, it is advisable to focus more on the computer-information preparation of students-ecologists.

Computer-information training of future environmentalists during their professional training can be considered in two aspects, which are in some way interconnected [1, p. 22]. On the one hand, the mastery of computer science and related disciplines must form the knowledge, skills and abilities required both for the study of special disciplines and for future professional activities [1, p. 23]. On the other hand, the basis for the professional orientation of teaching should be the principles of professional consistency, integrity, continuity, consistency, logical consistency [15, p. 687]. The implementation of these principles requires the use of facilities, methods and technologies of mathematical modeling of environmental objects, reflected in the sets of typical tasks that arise in practice, and the developed method of their solution, using the capabilities of modern information and communication technologies [1, p. 23].

The use of modern web technologies enables to significantly expand the tools of higher education system, in particular through the use of electronic educational resources.

H. Stetsenko pointed out the following definition of educational web resources: «These are educational electrical resources located in the web space of a local or global network in the form of various formats (text, graphics, archival, audio and video formats) [12, p. 10].

Educational web-resources include electronic learning tools, which are the basis for the use of web technologies. Scientists O. Spivakovskiy, N. Kushnir, N. Valko, M. Vinnyk (2017), R. Hurevych, M. Kademiia, M. Koziar (2012), M. Shyshkina, M. Popel (2016), H. Kravtsov (2015), H. Tkachuk (2011) and others are defined as information technologies, the use of which enables the processing and use of web resources (text, graphics, audio, video), connected by hypertext links and computer networks hosted in the web space (local or global).

H. Tkachuk describes the peculiarities of the operation of web technologies: the technical basis - local and global networks (such as the Internet); the organization of web resources in the network is carried out using hypertext technology; browsing web resources is done with the help of a bug viewer; use of search systems for web resources; an unlimited number of users who can download and browse web resources [21, p. 26]. 
R. Hurevych, M. Kademiia, M. Koziar classified educational web resources for the purpose of application in the following way: for the independent work of students or pupils; in order to prepare the teacher for classes; for self-education of a teacher; with the purpose of organizing practical work in class; for the organization of extra-curricular work on disciple $[18$, p. 44]. At the same time, the researchers identified the following forms of conducting classes in universities with the use of webresources: presentation, research, virtual experiment, laboratory work, thematic project, electronic quiz, knowledge control, elective course, network project, individual training, consultations, network game, virtual tour, press conference, creative report, remote olympiads, telecommunication projects, web quests, etc. To improve the skills of the teacher, the researchers pointed out the following forms: work in network methodological associations, virtual pedagogical meetings, distance learning, participation in network projects, web quests [18, p. 44].

L. Raickaja and other researchers attribute the attractiveness of Internet technologies for the education sector to the fact that they create an environment that promotes the development of students' creative abilities by stimulating curiosity, irregularity and multivariate learning, the formation and development of a divergent (non-stereotyped) thinking, growth of motivation [22, p. 74].

In the conditions of digitaliztion of higher education institutions, the use of electronic resources, in particular sites for educational purposes, electronic textbooks, video collections, is aimed at increasing the level of students' professional training [13, p. 178].

Unresolved aspects of the problem. The current state of computer-information preparation of students-environmentalists does not fully meet the requirements of their future professional activities. The issue of developing object-oriented software and educational resources aimed at improving the quality of the professional training of students in environmental specialties, in particular, their computer-information competence, is not fully solved.

The purpose of this article: creation and use of an information reference system for rare species of animals as a computer tool for the formation and development of professional competence of future ecologists and biologists in Ukraine. 


\section{Educational project Little Zoo - information reference system for environmentalists}

Designing the created information and reference system aimed at the formation and development of professional competencies of future environmentalists, contains a number of mandatory stages: the study of the subject area, the development of the architecture of the system, the implementation of the project, the implementation of the system.

The study of the subject area involves the following steps: development of the specification of the activity in the subject area, analysis of the activity in the subject area, including structural and logical analysis of the activity and analysis of the ways of the probable achievement of the determined result, analysis of the strength and cohesion of the components of the domain, analysis of system productivity and economic analysis [1, p. 23; 11, p. 89].

In the process of creating the architecture of the system, it is necessary to elaborate the specifications of the requirements for the projected system, the conceptual models of the subject area, the specification of the data processing of the projected system, the specification of the user interface of the system, specification of the subject domain activity taking into account the implementation of the system [25, p. 30].

The developed information and reference system for teaching the discipline «Information Technologies» for future ecologists was called «Little Zoo», which means «small zoo». The name of the project reminds us that there are few rare animals on our planet, a large number of species are endangered, so we need to protect the animals and the ecology of the world as a whole.

\section{Comparison of ecological web resources}

Before designing an educational web resource, we must look at similar training web-resources related to the work technology systems, to benchmark them and draw some conclusions. During the research, several information resources of the ecological direction were compared, and certain disadvantages and advantages were found in comparison with the developed system.

Animal reference resources, including «Practical Science», «Nature and Animals», «Cats-catalog», «Rare and Endangered Species» sites, were compared with the following characteristics: 
- content fullness;

- design corresponding to the ecological direction;

- search by main name;

- the ability to search for certain characteristics of the animal.

Students have considered each of the mentioned software products, and in the course of the educational discussion with the teacher concluded that the data resources have both advantages and certain functional disadvantages. The result of the web-resource comparison is presented in Table 1 .

Table 1

Comparative analysis of information resources about animals

\begin{tabular}{|l|c|c|c|c|}
\hline \multirow{2}{*}{ Characteristics } & \multicolumn{4}{|c|}{ Information resources about animals } \\
\cline { 2 - 5 } & $\begin{array}{c}\text { Practical } \\
\text { Science }\end{array}$ & $\begin{array}{c}\text { Nature and } \\
\text { animals }\end{array}$ & $\begin{array}{c}\text { Cats- } \\
\text { catalog }\end{array}$ & $\begin{array}{c}\text { Rare and } \\
\text { endangered species }\end{array}$ \\
\hline Content fullness & - & + & + & - \\
\hline $\begin{array}{l}\text { Design that meets the } \\
\text { environmental stress }\end{array}$ & - & + & - & + \\
\hline $\begin{array}{l}\text { Ability to search by } \\
\text { main name }\end{array}$ & + & + & - & - \\
\hline $\begin{array}{l}\text { Ability to search for } \\
\text { certain characteristics } \\
\text { of animals }\end{array}$ & - & - & - & - \\
\hline
\end{tabular}

Students are familiar with the criteria for creating a site:

- clear organizational structure and obtaining the necessary information in the shortest possible way (the rule of «three clicks»);

- color scheme of the site should never go beyond the comfort of perceiving the color and be unobtrusive;

- meaningful information content $[25$, p. 31].

In the course of the study, we have formulated additional requirements for the information resource in the discipline «Information Technologies», and related with it disciplines, suitable for use in the Internet:

- flexibility, convenience for administrators of the structure management system;

- the web site should support the use of graphic inserts, animations, which increase the emotional and financial component of the content, form a motivation; 
- creation of an educational content management system that would allow access to material about animals, provide a dynamic update [25, p. 32].

\section{Survey methodology}

The implementation of the Little Zoo information and reference system was done by the use of the Python programming language and the Django framework.

The selected software collectively allowed to realize the following possibilities:

- development of web resource design, system management and its components;

- easy installation and transparency of settings;

- web standards support (XHTML, CSS);

- the use of modules for connection (plugins) with a fairly simple system of their interaction with the code;

- the ability to automatically install and update the version directly from the admin panel;

- support of so-called «themes», with which easily changes as an external appearance, and ways of displaying data;

- the ability to edit templates right away in the admin panel;

- themes are implemented as a set of template files on Python;

- the presence of a significant number of «themes» and «plugins» libraries;

- the suitability of the potential of architecture for the implementation of hard solutions.

The process of developing an information and reference system included the following main steps:

1. After identifying the topic, the objectives and aims of the project, several information resources were considered and compared with each other.

2. At the next stage, a layout of the future information and reference resource was developed, for this purpose it was thought out the location of all the necessary elements on the page in the correct and user-friendly order.

3 . When creating a layout of the page, the Photoshop graphic editor was used, with the help of which the images and color scheme corresponding to the ecological direction were selected.

4. The search for educational material about rare and endangered species was performed to fill the page with text. 
5. At the end of the layout, HTML and CSS files were created.

6. Before designing a CSS file, the design of the page was developed using preprocessors such as SASS and LESS.
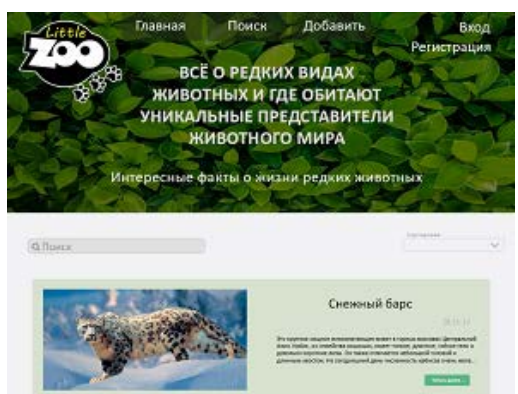

$=$
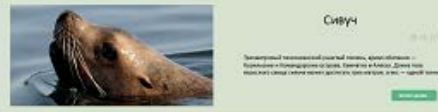

Fis

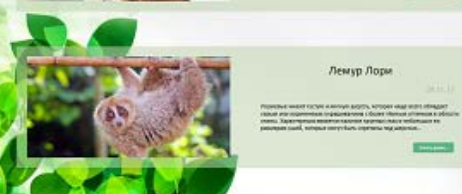

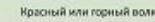
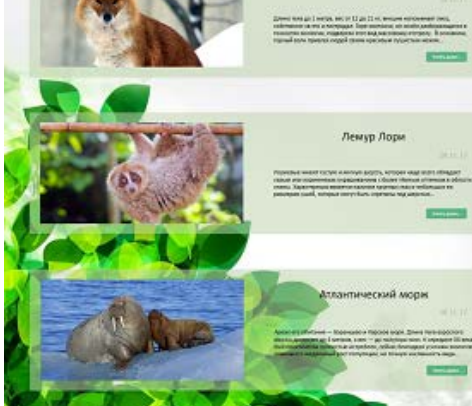

(8)

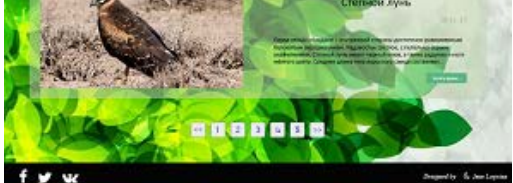

Figure 1. Template for the

Little Zoo Information System, developed in Adobe Photoshop

7. The SASS or LESS code was compiled into a CSS file; at this stage, the design of the information system can be considered complete.

8. Work with the framework of Django, which was used when creating the specified information resource.

9. Development of the adaptability of the page for different screen sizes.

\section{Findings}

The design for the information resource was developed in stages. Several layouts have been developed to know what kind of page they will look like. Templates were created using Adobe Photoshop tools such as brush, airbrush, pen, and pencil.

To create a template for the information system, the corresponding background images and page headers, as well as a few animal pictures, were selected. For the background, a picture with the image of the leaves was selected, in accordance with the ecological direction of the created resource. A resource image is also a picture with the image of the leaves, but darker in color, in order to make the text better visible.

In the program Adobe Photoshop a logo information system «Little Zoo» was created, a «hat» page was devel- 
oped, written text and relevant components were done. Then the main part of the filling system was created, which consists of information about rare animals. Each article has a picture, a title, a short text and a «Read more» button. Different styles, work with photography were applied to the articles.

A search box for animals by title and sorting of articles in a different order was also added. The bulk contains pagination - that is, numbering pages. Then the «basement» of the page is placed, with the help of which users have the opportunity to share the article on social networks. The formed layout of the page of the information system «Little Zoo» is presented in Figure 1.

Then the conversion of the created page layout into the code written in the preprocessor language was made.

The structure of the information system includes three inlays: the main page, the search page and the page to add a new article. On the main page there are articles about rare animals; The search page allows you to find any kind of animal with several characteristics; Third page allows the user to create his own article (after filling out all required fields on the page «Add» the article will be published on the main page of the system). The on-screen form of the information and reference system, consisting of three inlays, is given in Figure 2.

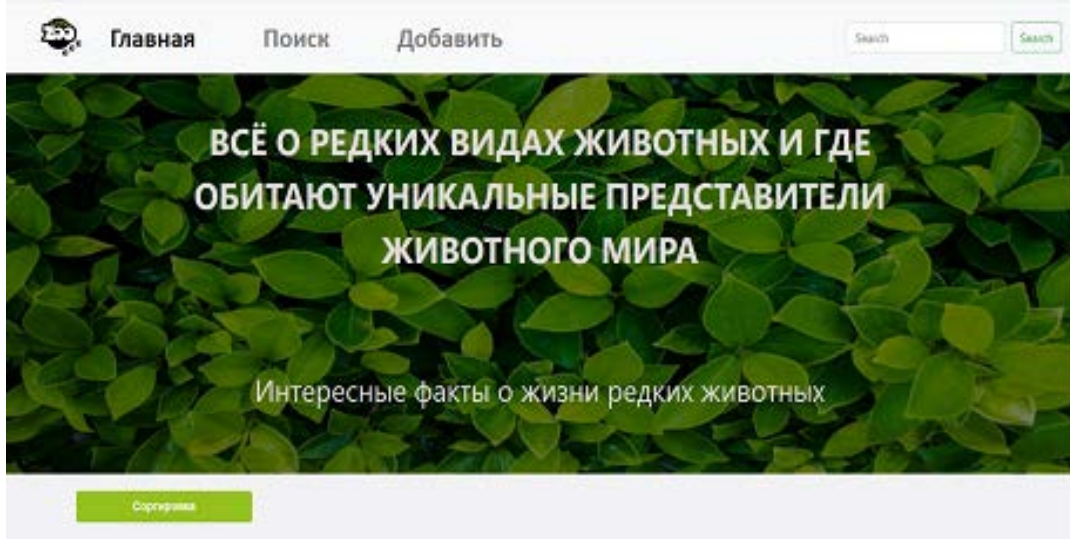

Figure 2. Screen form of reference system «Little Zoo», which consists of three inlays 
The use of information resources is carried out within the three roles:

1. An administrator - has extensive capabilities to work on a site, such as deleting an article or editing it, as well as adding own articles.

2. Unregistered user - has certain limitations, in particular, it can only view existing articles on the main page or find certain articles in the «Search» insert.

3. Registered user - all the same as the unregistered user, with one advantage - the ability to replenish the database by own articles. To do this, go to the «Add» tab, fill in the fields containing the animal's characteristics, then download the picture, click the «Add» button, and the article will appear on the main page.

Figure 3 shows diagram of precedents concerning above-stated roles in the information reference system.

The MySQL database, which was developed for the Little Zoo information system, includes more than four tables that contain highly structured data with fields and records. The main database tables of the information system contain the following information:

- table Users - with users data;

- table Articles - with data about articles on the site;

- table Blog_article - with animal characteristics data;

- table Animals_news table - with data of news about animals on the site.

The Users table, created to store user data, consists of fields such as «id» (serial number), «name», «password», «e-mail».

The Articles table for storing article data on the site contains the fields: «id» (the serial number of the record is automatically assigned), «article title», «short description», «article text».

The structure of the Blog_article table with the animal data which is considered in the articles was provided on the Figure 4. The database table contains the following fields for the animal's characteristics:

- id - serial number of the article;

- name - animal name;

- type - type of animal;

- class - class of animal;

- family - a unit, a family;

- habitat - habitat area;

- information - information about the animal; 


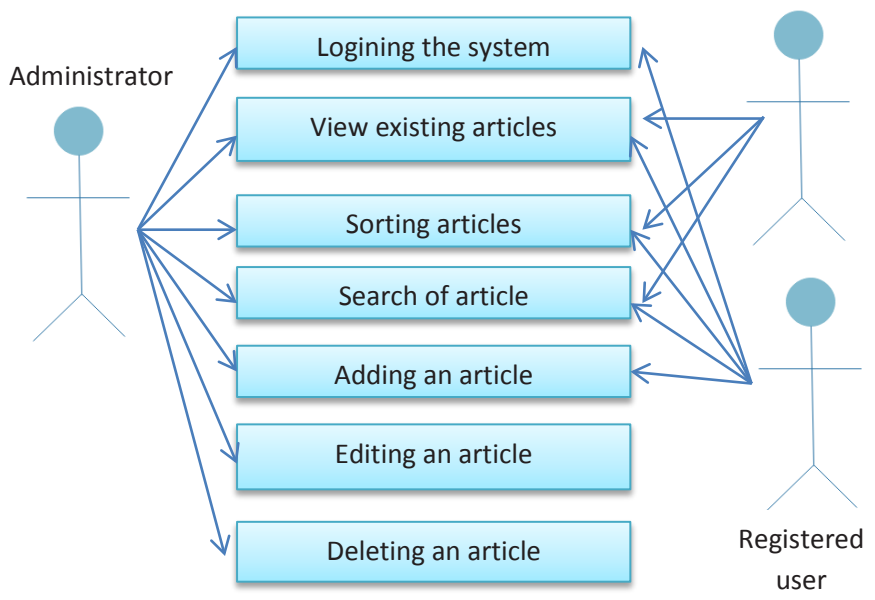

Figure 3. Diagram of precedents in the information reference system

- image - a way of representing an animal;

- created - the date of creation of the article;

- updated - date of article editing;

- exchange processes - exchange processes;

- environment - living environment;

- method_of_feeding - way of feeding the animal;

- article_user_id - the relationship between the user and the article.

Figure 5 shows model of activities in the information reference system.

Appointment of any information system - getting the user the most accurate information on a topic of interest to him [14, p. 98]. Often the choice of an article takes place under the hierarchy of the help sections. Reference systems are usually combined with search ones. It is the reference systems that solve all the tasks for providing consumers with regulatory information. Reference systems have a number of unique features, including:

- the ability to compactly store large volumes of information;

- the ability to display structured information stored;

- the ability to quickly find the necessary data or certain fragments [25, p. 30]. 


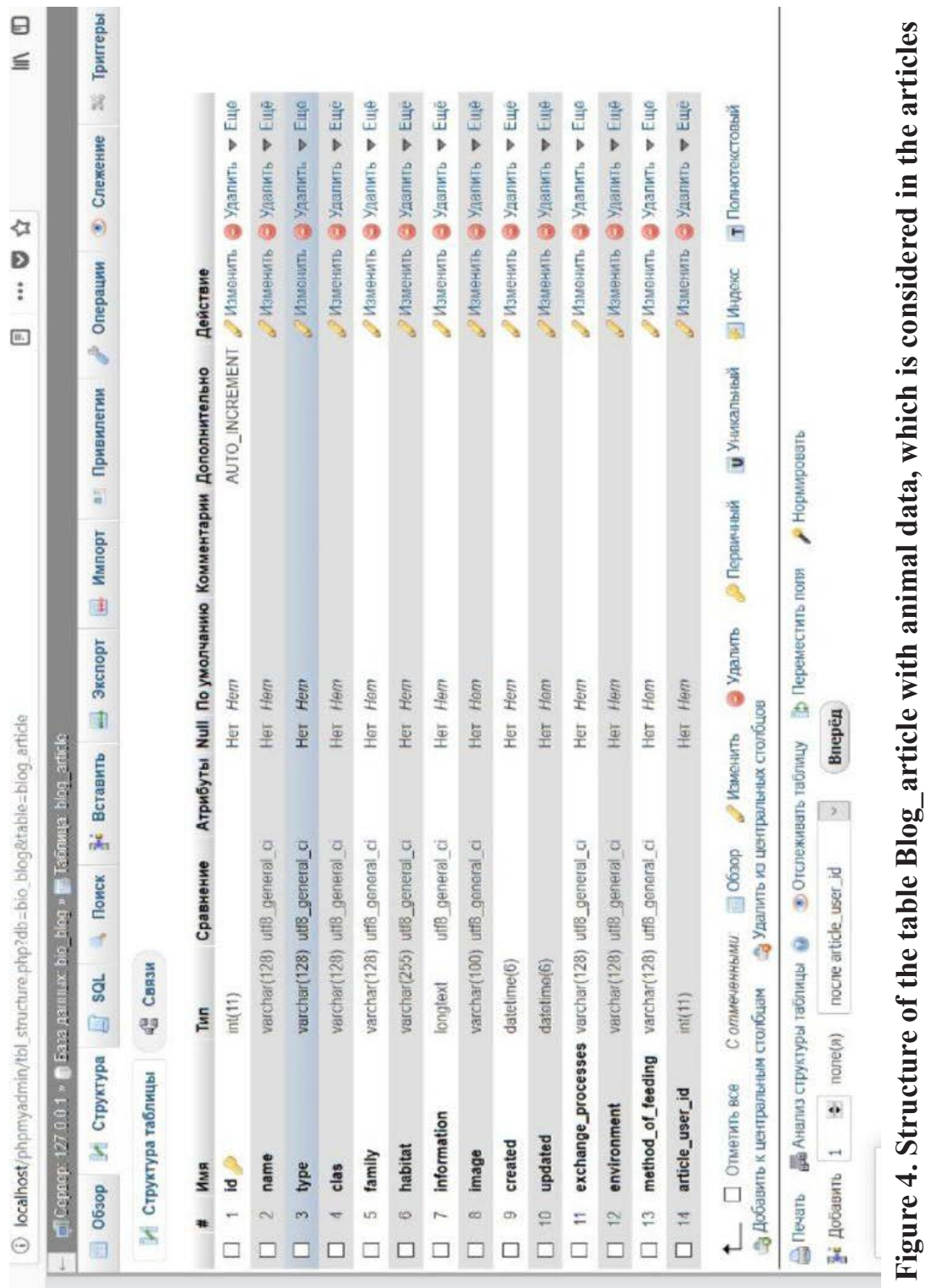




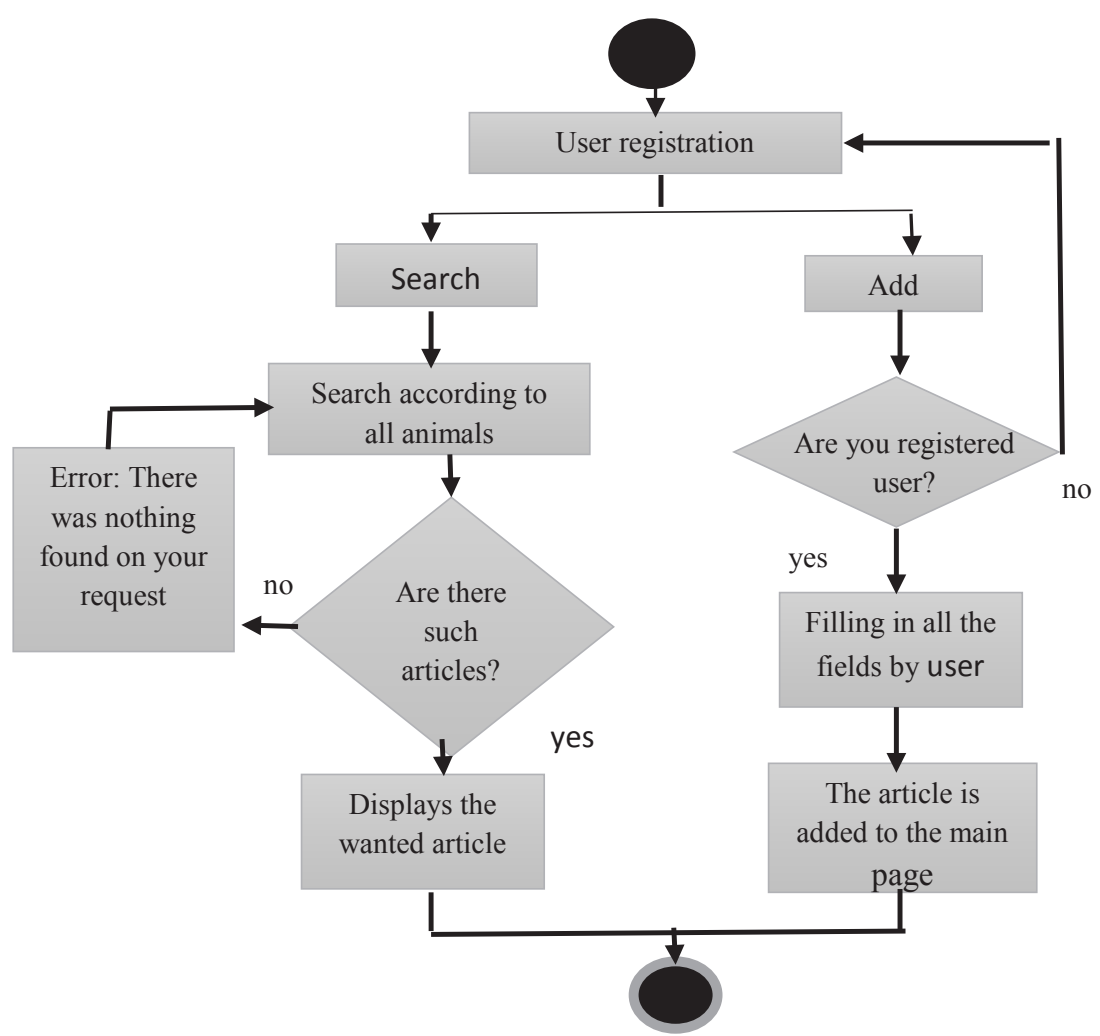

Figure 5. Model of activities in the information reference system

Figure 6 demonstrates the diagram of the sequences in developed information reference system.

On the main page of the Little Zoo information system, you can search by article title, or go to another Search tab and find a specific animal with certain characteristics.

In this window, forms are presented to fill the criteria for each cell of the database, which contains the following fields (Figure 7): name; type; class; detachment; family; habitat; information about the animal; exchange processes; eaten food. 


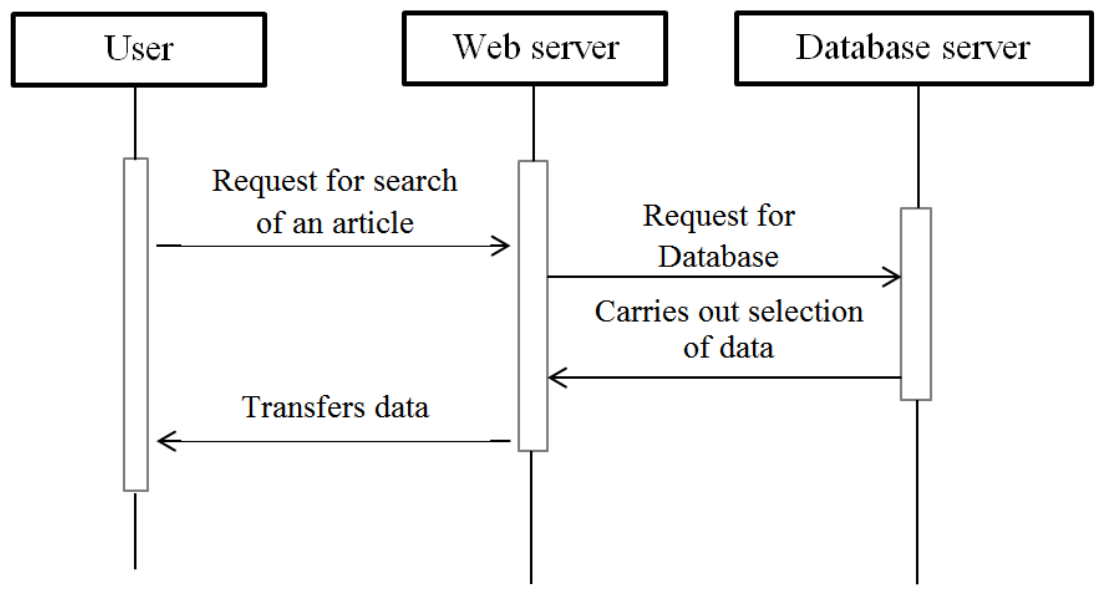

\section{Figure 6. Diagram of the sequences in developed information reference system}

Formation of requests in a resource occurs by entering the parameters of the user, which requires finding a certain type of animal (located on the right side of the page) (Figure 7). Filling in the appropriate options and the «Search» button allows you to find the animals for the characteristics entered.

The search result may have one or more articles, depending on how many fields the user filled or when the same parameter has some types of animals. Figure 8 shows the result of the search of animals according to one common parameter, namely - «habitat» - water.

Thanks to the web-based learning resource, students can search for a rare or endangered animal by one or more characteristics. The system also provides for the possibility of assimilating educational materials by sorting articles about animals in the right order.

Thus, the organization of training on the basis of personality-activity, computer-aided approaches, which involves the students in solving the tasks of designing and programming of web-resources, as well as the creation of conditions for interaction between the teacher and the student ensures the effective formation of the professionally important qualities of future ecologists and biologists. 

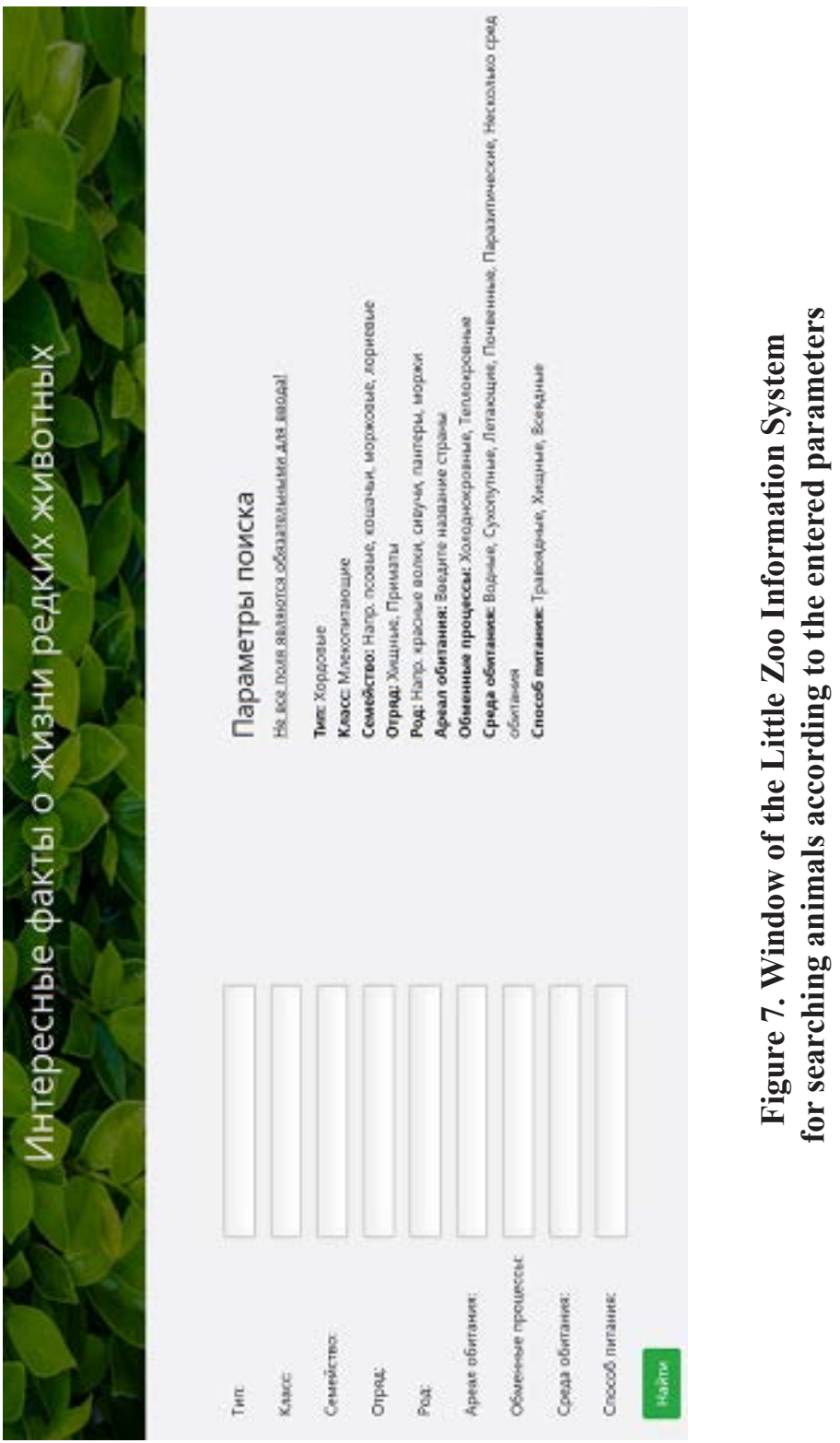


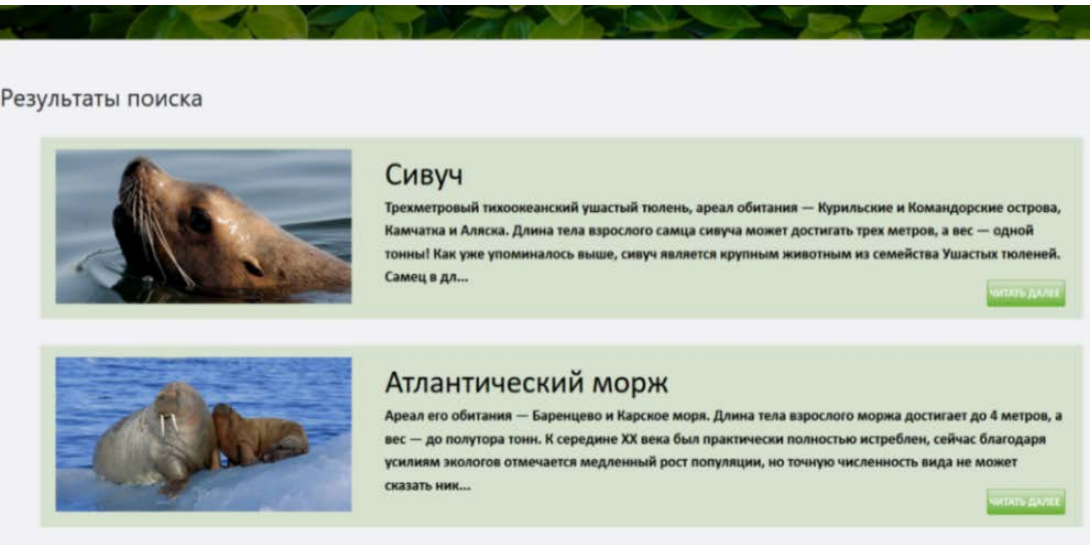

Figure 8. The result of the search of animals according to one common parameter

The mentioned information and reference system is successfully used at the Kherson State University in studying the discipline «Informatics and Systemology» by students of specialties 101 «Ecology» and 014 «Secondary education (Biology)», as well as in studying the discipline «Information technologies and technical means of correctional training» by students of specialty 016 «Special Education».

The acquaintance and work of the students with the learning resource is carried out within the framework of such classroom topics as «Information Systems and Technologies», «Possibilities of Using Information Technologies in Future Professional Activities». The interest of students in this reference system is due to the fact that registered users can add their own articles about rare and endangered animals, thereby expanding and updating the database of the resource. Such an active creative task contributes to the development of cognitive and intellectual activity, students' information competence, and also adapts to the real conditions of future professional activity.

\section{Conclusions and future work}

As a computer tool for the formation of professional competence of students of specialities 101 "Ecology", 014 "Secondary education (Biology)" of the education level «Bachelor» it is proposed to use the informational 
system for educational purposes «Little Zoo», aimed at solving the tasks of computer-information training.

The created information resource in the context of supporting the teaching of disciplines «Informatics and Systemology», «Information Technologies and Technical Means of Correctional Training» for students of higher educational establishments allows searching for rare and endangered species of animals among structured data based on a user-generated query. The result of this search is a list of animals that match the parameters of the request, with information about each of them.

The developed system will allow users (the future ecologists) to save time compared to the usual search, which is presented in most of the existing web resources of environmental focus.

During the design, students determine the purpose and tasks of learning through the use of computer tools, analyze existing analogs of the ecological web-resources, identify the main requirements groups, design information architecture, specific to the site for educational purposes [25, p. 35]. The application of this topic in the educational process of the Kherson State University is aimed at the development and improving of digital competences for future ecologists and biologists through the active introduction of new educational technologies, the use of opportunities for the information space, and the cooperation between teacher and student.

The functionality of the information and reference system allows registered users to add their own articles, to expand the database of the resource. Thus, the use of the developed computer tool «Little Zoo» in the teaching of disciplines «Informatics and Systemology», «Information technologies and technical means of correctional training» is aimed at forming the professional competence of students of specialties 101 «Ecology», 014 «Secondary education (Biology)», 016» Special Education «not only due to consideration of the system of theoretical positions, methods and technology of working with certain hardware and software, but primarily due to the practical use of IT tools in the profession on the level of modern and perspective requirements.

Further research requires the development of object-oriented software and training resources aimed at improving the quality of the professional training of students of environmental specialties in a modern university. Future work should also be oriented on the features of data storage in the design training web site, database structure, browser supports and mobile devices. 


\section{References:}

1. Sherman, M., Stepanenko, N., \& Felbush, A. (2017). Pedagogical basis of developing of educational web resource in the discipline «Informatics and Systemology» for future ecologies. Information technologies in Education 32: 21-39. (in Ukrainian)

2. Sherman, M., \& Stepanenko, N. (2011). Information technology in ecology. Kherson: Oldi-plus. (in Ukrainian)

3. Sherman, M., \& Stepanenko, N. (2008). Information and communication technologies in the training of future ecologists in the conditions of the agrarian university. New technologies of teaching, 54: 7-10. (in Ukrainian)

4. Biletska, G. (2014). Directions of improvement of natural-scientific preparation of future ecologists in higher educational institutions. Pedagogical process: theory and practice, 2: 17-23. (in Ukrainian)

5. Kovaltchuk I. (2002). Experience of the solution of problems in geographical level education. Problems of continuous geographical education and cartography, 3: 16-18. (in Ukrainian)

6. Gorelov, A. (1998). Ecology. Centre, Moscow. (in Russian)

7. Concept of ecological education of Ukraine. (2002). School principal, 16(208): 20-29. (in Ukrainian)

8. Kovaltchuk, I. (2004). Didactic bases of training of specialists of an ecological direction in the system of continuous professional education: problems and prospects. In: Theoretical and methodical bases of studying of natural and mathematical disciplines in professional educational institutions: prospects of the XXI century: 155-184. Lviv: Spolom. (in Ukrainian)

9. Sherman, M., \& Stepanenko, N. (2010). ICT in the professional training of future ecologists in the conditions of the agrarian university. In: Procedings of International. scient.-pract. conf. "Balanced environmental management: modern view, tendencies and prospects". Kherson: 204-205. (in Ukrainian)

10. Symonovs'ka, M. (2006). The methodical aspects of the training of future ecology teacher. History of the Ukrainian geography. Ukrainian scientifictheoretical magazine, 2(14): 78-82. (in Ukrainian)

11. Makarova, N. (2006). Information science. Finance and statistics, Moscow. (in Russian)

12. Stetsenko, H.V. (2010). Methodology of Applying Educational webresources to Informatics Teachers' Training. - Manuscript. Thesis for the Degree of Candidate of Pedagogics in Speciality 13.00.02 - Theory and Methodology of Teaching (Informatics). Dragomanov National Pedagogical University, Kyiv.

13. Spivakovskiy, O., Kushnir, N., Valko, N., \& Vinnyk, M. (2017). ICT Advanced Training of University Teachers. In: 13th International Conference on ICT in Education, Research and Industrial Applications: Integration, Harmonization and Knowledge Transfer. Kyiv: CEUR-WS, 1844: 176-190.

14. Samchynska, Y., \& Vinnyk, M. (2017). Decision Making in Information Technologies Governance of Companies. In: 13th International Conference on ICT in Education, Research and Industrial Applications: Integration, Harmonization and Knowledge Transfer. Kyiv: CEUR-WS, 1844: 96-110. 
15. Zaytseva T. (2016). The Introduction of the Competence-based Approach in Educational Process of Training of Skippers. In: 12th International Conference on ICT in Education, Research and Industrial Applications: Integration, Harmonization and Knowledge Transfer. Kyiv: CEUR-WS, 1614: 687-699.

16. Samchynska, Y., \& Vinnyk, M. (2014). Specific features of educational software promotion at Ukrainian market. Actual problems of economic, 7(157): 534-540.

17. Biletska, G. (2003). Training of a qualified ecologist as one of the ways of solving environmental problems. The collection of works on Ukrain. scien.-pract. conf. materials «Solutions of environmental problems of the urbanized territories: science, education, practice», 5: 156-158. (in Ukrainian)

18. Hurevych, R., Kademiia M., \& Koziar M. (2012). Information and communication technologies in professional education. Lviv: Spolom.

19. Shyshkina, M., \& Popel, M. (2016). Cloud based learning environment formation for mathematics disciplines learning using the SAGEMATHCLOUD (guidelines). Information technologies in education, 1(26): 148-165. Available at: http://ite.kspu.edu/home

20. Kravtsov, H. (2015). Methods and technologies for the quality monitoring of electronic educational resources. CEUR Workshop Proceedings.

21. Tkachuk, H. (2011). Methods of using educational web resources in future Informatics teachers' training. Uman: Vydavets «Sochinskyi».

22. Raickaja, L. (2011). Didactic and psychological basis of using Web 2.0 technologies in higher professional education. Moscow: MGOU.

23. Simonovich, S. (200). Computer science. Basic course. 2nd ed. St. Petersburg: Piter. (in Russian)

24. Afonin, V., \& Makushkin, V. (2009). Intelligence robotic systems: course of lectures. Internet University of Information Technologies, Moscow.

25. Sherman M., Samchynska Y., \& Kuzheliuk N. (2019). Designing a web resource for studying the ARDUINO platform as a means of generating the professional competence of furure engineers-programmers with a higher education level "Master". Information Technologies in Education, 3(40): 28-37. 